\title{
Deliverology in Community Economic Development: Enhancing Results Frameworks and Performance Measurement
}

\author{
Trevin S. Stratton, BPAPM, MSc, PhD \\ This paper will assess the viability of implementing an alternative delivery model and \\ performance measurement framework - commonly known as 'deliverology' - at the level \\ of community economic development. First, a review of relevant literature on traditional \\ economic development delivery models and performance metrics is conducted to \\ determine strengths and weaknesses. Next, a deliverology approach is defined and \\ analyzed to determine whether such a model can address the weaknesses of more \\ traditional approaches. The results indicate that a deliverology approach has many \\ potential advantages for economic development service delivery and addresses many of \\ the weaknesses of current models and frameworks. Since deliverology remains rather \\ new compared to more traditional approaches, further research in terms of a case study in \\ a large urban municipality is recommended as a way to test the applicability of \\ deliverology to community economic development.
}

Keywords: deliverology, performance measurement, results and delivery framework, community economic development, service delivery model

\section{Introduction}

National and global economic changes have communities grappling with new opportunities and challenges every day. New technologies, global supply chains, a fluctuating Canadian dollar, a changing labour market, and international competition have disrupted the sectors and industries that have traditionally formed the bedrock of many economies. Municipalities must compete fiercely with other communities - both domestically and internationally - to attract investment, businesses, talent, and funding.

Indeed, the Brookings Institution finds that Economic Development Organizations (EDOs) are struggling with major disruption, with business attraction and expansion activity down 50 percent (Donahue and McDearman, 2016). In response, EDOs are trying to remake themselves through new strategies focused on cultivating long-term economic assets and enhancing the competitiveness of firms (Donahue and McDearman, 2016).

At the same time, a creative and knowledge-based economy driven by ideas, innovation, knowledge, and collaboration have emerged as key drivers of economic growth. Many local businesses have also found themselves in an opportune position to take advantage of new consumer demands for original and local place-based products and services. 
To survive and flourish in this fast-paced competitive environment, communities must foster agility, flexibility, adaptability, and dynamism in their EDOs. Yet, many communities often find themselves mired in bureaucratic stagnation as they continue to use dated delivery models and performance measurement frameworks.

This paper will assess the viability of implementing an alternative delivery model and performance measurement framework - commonly known as 'deliverology' - at the level of community economic development. First, a review of relevant literature on traditional economic development delivery models and performance metrics is conducted to determine strengths and weaknesses. Next, a deliverology approach is defined and analyzed to determine whether such a model can address the weaknesses of more traditional approaches.

The results indicate that a deliverology approach has many potential advantages for EDO delivery and performance, and addresses many of the weaknesses of current models and frameworks. Since deliverology remains rather new compared to more traditional approaches, further research in terms of a case study in a large urban municipality is recommended as a way to test the applicability of deliverology to community economic development.

\section{Delivery Models}

An increasing number of communities are investing in formal economic development departments or organizations, leading to considerable debate in the literature over where the effort should be housed (Bowen, Rubin and Hill, 1991; Rubin, 1999). This literature review will focus on the two most common economic development delivery models at the local-municipal level: the internal model where an internal department reports through the administration to municipal council, and the external model in which a not-for-profit corporation provides economic development services and is governed by a board of directors.

\section{Internal Delivery Model}

In the internal model of economic development, staff members are accountable to Council for the delivery of economic development programming. The economic development office may be either a stand-alone department or integrated with another department such as the planning department (Frith, 1993). Policy is set by Council and staff members are employees of the municipality. In smaller municipalities, economic development activities may be the responsibility of the clerk, city manager/chief administrative officer, planner, or economic development officer.

In some communities, economic development is a sub-department or division within a larger planning, community services, or similar department. In smaller rural communities, there may be a single staff member who manages the municipality's economic development activities (Douglas and Chadwick, 2003; UBCM, 2010). In all cases, the internal economic development 
department reports to the Chief Administrative Officer and is formally governed by the elected municipal Council and Mayor.

The advantages of this model can include internal alignment with council and closer communication, collaboration and coordination with other municipal departments; integration of administration with municipality; potential for more sustainable wages and benefits; and less expectation for sourcing additional funding (Thompson, 2010; Myhal, 1994; Blakely \& Leigh, 2009). The municipal role in economic development also includes the important and undervalued contribution of core service delivery such as infrastructure and community planning, which can be facilitated by an internal economic development department (UBCM, 2010).

Incorporating the functions of the corporation into the structure of the municipality provides the opportunity to streamline administration by eliminating separate board meetings, incorporation of finances with city operations, eliminating a separate set of audited books and administration (Myhal, 1994). Operating as a department also offers the possibility of increasing collaboration between departments and economic development staff.

When integrated as a city department rather than a stand-alone corporation, policy and direction are streamlined and municipal protocols can be adopted regarding committees and appointments. As well the economic development strategic plans can be more directly integrated with other municipal strategic plans. In the internal model, funding is generally from the municipality with less expectation for staff to source private-sector funding. The potential for more sustainable wages, benefits, and pensions can help attract and retain highly-skilled economic development professionals. When part of the municipal function, it gains access to established municipal services including human resources, finance, geographic information systems, and enables the economic development office to deliver programs that require coordination across multiple departments.

\section{External Delivery Model}

External organizations are typically created to provide a single service; provide a highly specialized service; allow for arm's length decision-making; separate the service from the political process; remove certain functions from the public eye; establish self-funding businesslike units; involve business people in decision-making; or to provide for multijurisdictional representation (Myhal, 1994).

In the external model, a not-for-profit corporation and staff members report to the board of directors of the corporation often through a General Manager or Chief Executive Officer (CEO). The corporation is not under the direct control of the municipal council, but is one step removed from the municipal administration (Siegel, 1994). The board of directors sets policies and is accountable to obtain funding for payroll, operations, and programming. A study by McCabe found that 85 percent or more of the revenue of most not-for-profit corporations come from the municipality in the form of operating grants (McCabe, 2007). The separation from municipal 
operations provides staff members with the opportunity to focus on economic development activities without distraction by other municipal matters.

Siegel (1994) suggests that there are four situations for which the use of these types of organizations is appropriate: 1) the service area is multi-jurisdictional, 2) the issue is intergovernmental, 3) flexibility in service delivery or organizational structure is required, or 4) the function benefits from arm's length delivery. The need for arm's length decision making is a rationale used when there is a need to separate decision-making from the political process.

A corporation offers the autonomy and provides ability to operate with a minimum of bureaucracy. In this way, the external model fosters working practices that are more closely aligned with the private sector than those of the public sector. A corporation provides the opportunity for business leaders to become fully engaged and accountable through membership on the board or leading activities and initiatives (McCabe, 2007). As well, stakeholders may be more likely to get involved and assist an external economic development office, providing expertise free of charge (Peterson, 1981). Operating as a separate corporation enables staff to conduct business differently than a municipal office does; for instance, being more aggressive and taking risks when it comes to business or marketing decisions.

Participants in one study suggested that the external model of service delivery allows for faster, more creative, proactive, and nimble decision-making when compared to the more bureaucratic and structured municipalities (Parker and Donaher, 2013). This is particularly important in an economic development office which often requires fast-paced decision-making in an environment of constantly shifting priorities based upon client needs. One explanation for the improved timelines is greater flexibility in the decision-making process. With less stringent requirements and procedures to adhere to, such as specified timelines of when and how agendas must be submitted and meetings scheduled, faster decisions can be made in the external model. Participants suggested that processes are faster in external corporations due to different levels of decision-making authority. Respondents indicated that more decisions are made by corporation staff instead of moving up to the Board of Directors. With greater organizational flexibility, fewer decision-makers need to be involved, less communication is required, and timelines are shorter.

\section{Accountability vs. Flexibility}

In general, the arguments for one model or another tend to mirror the long-standing debate arising from New Public Management of autonomy versus control in traditional line departments and arm's length organizations (Cain, Risser and Stratton, 2010). Parker and Donaher find that economic developers believe there is tension between the speed and flexibility of decisionmaking and accountability (Parker and Donaher, 2013).

Municipal departments generally garner more public attention and therefore may be held more accountable than external organizations (Myhal, 1994). There is a perception of greater 
accountability and less opportunity for decisions that primarily benefit certain businesses as they might with a board of directors (Myhal, 1994; Bowen, Rubin and Hill, 1991; Rubin, 1999). Three of the six municipal departments in Parker and Donaher's study indicated that participants believed transitioning to the external model would decrease their organization's accountability, although opinions were mixed on whether this would be an overall positive or negative change (Parker and Donaher, 2013). With a separate corporation, the board sets policy and direction which may or may not always directly align with the policy of council, which can lead to significant conflict (Myhal, 1994).

External agencies are often seen as leading to fragmentation, hindering public understanding of government and often perceived to be less accountable (Graham, 1993). The basic conflict between flexibility and efficiency on the one hand, and accountability on the other, pervades many discussions on this topic (Myhal, 1994). However, there are two mechanisms to link municipal councils to external organizations: representation on the board and control of the corporation's budget (Graham, 1993). Parker and Donaher find that municipalities are highly accountable given their formal processes, while corporations have taken steps to demonstrate accountability through performance measurement and public reporting (Parker and Donaher, 2013).

A UBCM report asserts that the majority of local governments with an economic development function operate an internal model, with some combination of a formal department and less formal mechanisms (UBCM, 2010). In contrast, Blais and Redden find that external organizations are more common and perhaps better suited to larger communities (Blais and Redden, 2009). It should be noted that this discrepancy in findings could potentially be due to the different jurisdictions of British Columbia and Ontario.

A challenge raised by several participants in both delivery models is the involvement of governing bodies in the operations and management of the organization. This is an issue with councils, advisory committees, and boards regardless of the governance structure. It is much easier for councillors to engage in the operational matters of an in-house municipal department than an arm's length organization; providing an external agency with a buffer from political interference in the office's operations. However, participants in Parker and Donaher's study suggested that performance measurement needs and issues should not differ between internal and external models; thus, they did not see any major difference in how organizations of both models would demonstrate accountability (Parker and Donaher, 2013).

A number of communities have also attempted to harmonize these two models into a hybrid. A UBCM report also mentions that many local governments are embracing a blended option with elements of both an in-house and arm's length delivery model (UBCM, 2010). Thompson notes that committees are often created to provide strategic direction on economic development matters and especially in the case of municipal economic development offices, to create a link to the private sector (Thompson, 2010). However, the advisory committee does not deal with 
matters of human resources, finance, information technology, etc. as would a municipality. Instead, the committee focuses on strategic matters pertaining to economic development (McCabe, 2007). Finding the appropriate delivery model can involve refining this hybrid approach over time to reflect the changing circumstances, needs and priorities of the local government.

The literature review reveals that identifying the optimal delivery model should depend, in large part, on understanding the goals and priorities of an organization, potential partnerships, and community characteristics (Blais and Redden, 2009; Blakely and Leigh, 2009; Thompson, 2010; UBCM, 2010). Blais and Redden also suggest, "the decision to go internal or external is really a local one" (Blais and Redden, 2009, p. 20). However, only $21 \%$ of all respondents in the UBCM study felt their model is highly effective, suggesting improvements can be made across the field (UBCM, 2010).

\section{Performance Measurement}

The literature on performance measurement in economic development organizations makes clear that there are no universal standards for key performance indicators or data sources. Nonetheless, professional associations such as the Economic Developers Association of Canada and Economic Development Council of Ontario have begun encouraging the use of these indicators. Blais and Redden state the following reasons for EDOs to track activity and performance: providing public accountability; assisting with human resources management; using results to improve performance; and identifying the return on investment. An effective economic development office must perform, measure, and communicate these results (Blais and Redden, 2009).

For years, the officials heading most of economic development initiatives tracked their efforts with little more than output measures - for instance, the number of industrial contacts made or assisted, the number of meetings held or presentations made, the number of information packets or brochures distributed, the number of trade shows attended, and similar measures of activities. They focused on showing that they were trying hard (Ammons and Morgan, 2011).

More recently, as local governments have gained greater experience with economic development and as more attention has been directed to outcomes and accountability across the range of local government programs and services, the state of the art has begun to change. Now, economic development officials - and those who monitor their performance - are increasingly tuned in to a broader and more meaningful array of measures to document their performance (Ammons and Morgan, 2011). As a result, a number of performance measurement frameworks have been developed for EDOs.

Typologies 
Henry Hatry with the US Urban Institute has had a major influence on the thinking about performance measurement in economic development. Hatry argues that performance measures should be aimed at achieving clearly identified outcomes: "Outcomes are not what the program itself did but the consequences of what the program did" (Hatry, 2006). His framework and those based on his work use a logic model that focuses on the interrelated elements that organizations use to measure performance of an operation: inputs, activities, outputs, and outcomes. Building on Hatry's work, Angelou Economics has posited that performance measures need to be SMART: specific, measurable, achievable, relevant, and time-based (Angelou Economics, 2005).

The Regional Innovation Acceleration Network (RIAN) is a group funded by the US Economic Development Administration. RIAN is focused only on the direct impacts of Venture Development Organizations (VDOs) on the client firms and the improvement in the VDO's impact based on client reporting. RIAN identifies the following four impact measures and one performance measure that should be adopted by all VDOs: jobs created, wages paid, investments attracted, and revenues earned (EDAC, 2011). It is also essential that the impact, or change, over time resulting from VDO activity in its region is measured.

One of the most influential models used in business is the balanced scorecard. It conceptualizes a framework for evaluating performance metrics for both financial and operational measures that includes evaluating an organization's ability to create value moving ahead. The balanced scorecard was developed with the purpose of focusing the attention of a company's top executives on a short list of critical indicators of current and future performance (Kaplan and Norton, 1992). The model develops four perspectives: the customer perspective, the internal business perspective, the innovation and learning perspective, and the financial perspective (Kaplan and Norton, 1992).

There are myriad other performance measurement frameworks that can be leveraged by EDOs. The IEDC emphasized tying metrics to an organization's mission, functions, scope of work, and resources (Ghosh and Chen, 2014). The Ontario Ministry of Agriculture, Food and Rural Affairs (OMAFRA) recommends tying performance measurement to the strategic planning process through logic models (OMAFRA, 2015). The Community Vitality Index measures the quality of life in a community (Parker, 2015). The Genuine Progress Indicator measures whether economic growth has resulted in an improved well-being of people by looking at economic, social, and environmental indicators (Parker, 2015). Continuous Improvement Measurement Systems not only emphasized the performance measurement process, but also the performance management system by adjusting processes and activities over time (Parker, 2015). Communities also have the option of using hard models or soft models, Northern Ontario Development Program frameworks or OMAFRA frameworks, or measuring research dollars or cost per job created. The number of performance measurement options available appears to have resulted in EDO confusion $-86 \%$ of EDAC members stated that there is not a recognized system or model on which they have based their performance measurement activities (EDAC, 2011). 


\section{Criticisms}

The performance measurement tools described in the previous section emphasize the importance of setting the right goal, since, in theory, goals should dictate which strategies receive resources. However, this is not often the case in practice. The pressure to quantify impact means that regardless of overarching goals, the success of specific initiatives is measured by their ability to contribute to traditional metrics. Thus, EDO decision-makers face a problem: their performance measurement must evolve, but they are limited to a set of strategies that appear to contribute to the existing standard for performance metrics.

Those who oversee and lead EDOs need to confront the fact that their performance metrics are deeply flawed. Rubin argues that success is mostly a matter of chance and that the EDO just happened to be in the right place at the right time. By insisting that every initiative meets a standard for job creation and capital investment that was never realistic to begin with, however, those that oversee EDOs are not only holding potentially important initiatives hostage, they are also actively driving unproductive behavior (Rubin, 1999).

The Brookings Institution has identified three ways in which EDOs skew performance metrics. First, EDOs often exaggerate their responsibility for outcomes. EDOs are not directly responsible for creating jobs, even when a company is enticed to relocate. By the time an EDO is involved in such a deal, the company has usually zeroed in on two or three locations based on factors inherent to the region. EDOs make a marginal difference in these cases. Yet, if the company does relocate, all of the jobs are tallied up as a measure of performance. (Donahue and McDearman, 2016)

Second, EDOs can buy metrics by providing financial assistance to firms. Because performance metrics are structured as if EDOs create jobs, they must somehow engineer a clear link between their efforts and a firm's actions. EDOs also need firms to give them data that they can use to quantify impact. Proving incentives and subsidies, regardless of whether they are justified, solves both problems - the EDO can point to the investment as proof that it caused certain outcomes, and can quantify those outcomes using numbers provided by the firm. Programs that bolster the competitiveness of existing firms have no such mechanism and therefore seem ineffectual in comparison according to traditional performance indicators. (Donahue and McDearman, 2016)

Finally, EDOs can also overstate how accurately they can measure impact. For example, when EDOs run programs that offer assistance to a group of firms, they usually claim credit for any positive outcomes that occur in the following year. They fail to account for selection bias (firms that receive assistance are more likely to achieve desired outcomes anyway) by comparing participating firms with a peer control group. These and other considerations significantly reduce the impact attributable to the EDO (Donahue and McDearman, 2016). A Pew report highlights state analyses that estimated that $80-90 \%$ of jobs attributed to incentive programs either replaced existing jobs or would have been created regardless of EDO involvement (Pew, 2012). 
Traditional delivery models and performance measurement frameworks have certainly had some success in improving EDO performance, but progress has often been slower than desired. At times, progress is uneven: some economic development initiatives are making gains, while others are stalled. EDOs should rightfully be proud of their accomplishments, but few are completely satisfied. Which leads us to a significant question: what is holding EDOs back from optimal performance? The answer: execution.

\section{Deliverology}

While the delivery models and performance metrics surveyed in this paper focus on processes and measurement, deliverology places emphasis on implementation and execution. Governments are under increasing pressure to improve public services and stimulate economic growth.

Citizens now expect them to deliver results in shorter time frames, often at lower cost, and they may become dissatisfied if officials do not meet these expectations.

Although public-sector leaders may know what they want to deliver and have ideas about how to do it, it can be a struggle to translate a high-level vision into reality. Many governments fail to prioritize, spread their efforts across multiple projects, and increasingly must function with tighter budgets. The underlying issue, however, is that many governments lack a structured, disciplined process for delivering breakthrough results.

Frequently, plans fall by the wayside and reform goals remain unmet for a variety of reasons: political pressure can cause priorities and resources to shift, success can be difficult to measure, consequences for failed delivery are less obvious than in the private sector, and stakeholder motivations are not always transparent. The challenge for public-sector organizations is to find ways to execute their highest-priority objectives so that they have the greatest possible impact. (Barber, Kihn and Moffitt, 2011a)

The deliverology approach was developed specifically for this purpose. Encountering difficulties turning policy declarations into measurable outcomes, UK Prime Minister Tony Blair established the first delivery unit in 2001 based on the advice of deliverology guru Sir Michael Barber. Since that time, the deliverology approach has been implemented by governments across the globe from Albania to Tanzania - and forms the basis of the departmental results framework currently being used by the Government of Canada.

This section will address three key components of the approach: establishing a small team focused on performance, gathering performance data to set targets and trajectories, and having routines to drive and ensure a focus on performance. Through each of these components runs a critical thread: relationship building. The applicability of the deliverology approach to EDOs will then be assessed in comparison to more traditional delivery models and performance measurement frameworks. 


\section{Delivery Unit}

At the core of deliverology is the establishment of a delivery unit - a small group of employees focused exclusively on achieving impact and improving outcomes. The delivery unit constantly challenges performance and asks difficult questions. The unit should also consistently push for faster progress, knowing full well that the tendency of any system is toward inertia. As such, the delivery unit should be a permanent structure and an extension of senior leadership. (Barber, Kihn and Moffitt, 2011b)

The delivery unit should have a non-hierarchical relationship with the system, residing outside the traditional line department hierarchy. It should not be managed by any of the people or organizations it is trying to influence, nor should it directly manage those people or organizations. This independence will allow the unit to deliver difficult messages, but also sustain trust and credibility with actors in the system. There should be clear lines of communication and relationships between the delivery unit and the departments it oversees. (Barber, Kihn and Moffitt, 2011b)

Delivery units share several more key organizational-design attributes. The unit should designate a full-time (or nearly full-time) delivery leader who reports directly to the leader of the publicsector organization or system. In screening candidates for the delivery staff, leaders should look for five core competencies: problem solving, data analysis, relationship management, feedback and coaching, and a delivery mind-set. The delivery unit should also be small to preserve flexibility, allow selectivity in hiring, and promote a cohesive culture. (Barber, Rodriguez and Artis, 2016)

\section{Gathering Performance Data}

Among deliverology's most effective tools are targets - a prioritized set of measurable, ambitious, and time-bound goals - and trajectories, a projected progression toward these goals that creates a tight link between planned interventions and expected outcomes. (Barber, Kihn and Moffitt, 2011a)

While nearly all public-sector organizations set targets, many of these targets are somewhat vague or unmeasurable, or they operate under unclear time horizons. Targets should be both ambitious and realistic. An unambitious target can generate acceptance of incremental rather than transformational change, and an unrealistic one will discourage those responsible for achieving it. A delivery unit can play an important role in setting targets - perhaps brokering negotiations between system leadership and the relevant performance units-but its foremost role in this area is to ensure targets remain prominent for the entire public-sector system. (Barber, Kihn and Moffitt, 2011a)

For every target, the delivery unit should also develop a trajectory: an evidence-based projection of the performance levels the system will achieve as it pursues the target. Trajectories serve as a 
tool for understanding a system's progress toward its target and allow for meaningful debate as to whether a target is both ambitious and realistic. Presented well, trajectories have a powerful visual impact that can clearly communicate the gap between performance and expectation at any point in time. (Barber, Rodriguez and Artis, 2016)

Public-sector organizations rarely develop and use trajectories - in part because they can be difficult to establish, as evidence is sometimes unclear or hard to find. In addition, there is often great resistance to continuous performance measurement given the potential for failure. However, trajectories can be particularly useful since performance is not always linear over time. To develop trajectories, organizations can use benchmarks - historical comparisons, international peer comparisons with other performance units, or external peer comparisons with other systems - to determine performance trends in similar contexts. A second approach is to use interventions - for example, the impact on jobs from attracting a Fortune 500 corporation to a community and extrapolating the potential impact on the entire system. (Barber, Kihn and Moffitt, 2011a)

\section{Establishing Routines}

One of the most important contributions that a delivery unit can make is to establish and maintain routines: regularly scheduled and structured opportunities for the system leader, delivery-plan owners, and others to review performance and make decisions. Routines work because they create deadlines, which in turn create a sense of urgency. (Barber, Kihn and Moffitt, 2011a)

Many systems already have annual reviews in place and may question the need for more frequent check-ins. However, the lag between making a decision and seeing results is immense. More frequent routines help the system identify problems earlier and act faster. Three distinct routines - that vary in frequency, audience, format, and the type and depth of the information they provide - have proved effective. (Barber, Rodriguez and Artis, 2016)

Monthly notes are the most frequently occurring routine. Each note consists of a succinct summary of progress, current and emerging delivery issues, and key actions required. The progress reported in monthly notes can be at the level of leading indicators, as data for the target metric will not always be available. Monthly notes provide a tremendous opportunity for organizations to engage in timely problem solving and course correction. (Barber, Kihn and Moffitt, 2011a)

Stocktakes are quarterly meetings to review and discuss performance for each priority area in depth. Stocktakes are used to demonstrate the system leader's commitment to the delivery agenda, enable the system leader to hold individuals accountable for progress on targets, discuss options and gain agreement on key actions needed, share best practices and support interdepartmental cooperation, celebrate successes, and identify new policy needs. Participants should include the system leader, any other delivery-unit staff, and leaders from the relevant 
departments. Stocktakes rely heavily on data, maintain a focus on a sustained set of priorities, and ensures a high level of visibility and attention. (Barber, Kihn and Moffitt, 2011a)

Delivery reports are in-depth assessments provided every six months on the status of all of the system's priority areas. Delivery reports allow leaders to compare progress across priorities; identify actions for relevant departments, with dates and named responsibilities; and reassess the allocation of resources and attention based on each priority area's need and distance to targets. This is combined with recent performance against the trajectory, as well as data on any other relevant leading indicators, to generate an overall judgment on the likelihood of delivery for the priority in question. (Barber, Kihn and Moffitt, 2011a)

\section{Deliverology and Economic Development Organizations}

Many of the strengths of deliverology address the weaknesses of more traditional delivery models and performance measurement frameworks. Internal delivery models provide internal alignment, administrative efficiencies, and accountability, but lack the flexibility necessary to make quick decisions in a rapidly changing economic environment. External delivery models provide this flexibility and a close relationship with the business community, but lack more formal accountability mechanisms. Deliverology offers an alternative model: flexibility in execution through a non-hierarchical relationship with the system and strict accountability through a close relationship with line departments and frequent routinized progress reporting on performance trajectories.

Similarly, deliverology addresses the criticisms aimed at more traditional economic development performance metrics. The independence of the delivery unit is a unique strength of the deliverology approach that negates a number of issues arising from moral hazard in more traditional performance measurement frameworks. The Brookings Institution rightly points out that EDOs are often self-interested when it comes to performance measurement; exaggerating their responsibility for outcomes, buying successful metrics, and overstating how precisely they can measure impact. Thus, a conflict emerges between correctly presenting performance so the community can accurately assess its economic development and skewing performance metrics so that the EDO appears successful. Deliverology helps to resolve this conflict by separating responsibility for economic development initiatives and programs with the EDO and responsibility for performance measurement with the delivery unit.

Deliverology offers many strengths for EDOs to enhance their delivery models and performance measurement frameworks. Separate delivery units provide the independence and flexibility necessary for a focus on execution. Using trajectories to base performance metrics on benchmarks and interventions can help make EDO performance measurement less arbitrary and subjective. In addition, this approach can also help with the standardization of EDO performance measurements and the development of best practices based on norms. The routinization of delivery and performance can also provide EDOs with a constant emphasis on the 
implementation of economic development initiatives. Economic development is a field where there are a number of independent variables in the external environment that can impact EDO planning and performance. As a result, EDOs can point to exogenous factors as reasons for suboptimal performance. With deliverology, EDOs can be assessed on their reaction to these exogenous impacts as delivery and performance is routinely monitored and adjustments made.

In addition, there are further advantages to the deliverology model if private sector stakeholders are included in routinized performance reviews. Deliverology would then also allow EDOs to regularly work together with pursue community economic development, attract investment, assess the labour market, and make the EDO more efficient and effective. Including business owners would also help to build relationships in the private sector, thereby increasing the likelihood that businesses will share information with the EDO. Such an ecosystem of continuous economic improvement could help predict future challenges and opportunities and promote preventive - rather than prescriptive - care for local economies.

In essence, deliverology offers many promising advantages compared to current delivery models and performance measurement frameworks in community economic development. These advantages merit further consideration from EDOs to implement pilot projects to assess the viability of deliverology in practice.

\section{Conclusions, Limitations and Further Research}

The applicability of deliverology to community economic development is a novel idea and requires further research. While the approach has demonstrated success across jurisdictions and levels of government, there are certain unique factors in community economic development that must be assessed prior to a categorical endorsement of deliverology.

One potential limitation is the compatibility of deliverology with communities that already use external delivery models. In theory, a community would then have two arm's length organizations performing economic development functions - one responsible for planning and programming and another responsible for delivery and performance measurement. Since nonhierarchical arm's length organizations are generally considered to be less accountable than line departments, it is possible this system would exacerbate the problems EDOs already have with accountability. Alternatively, the delivery unit may be able to provide an additional level of accountability for the external corporation, thereby mitigating the risk involved. A third possibility is that EDO's that use an external delivery model may shift to an internal model after adopting a deliverology approach. These possibilities merit further investigation.

Another consideration is the size and cost of the delivery unit. Delivery units have demonstrated success with large federal, provincial, and state governments with a number of employees and significant resources. The potential for success in municipal or Indigenous governments at the community level is less proven. Community economic development is often hampered by limited resources, restricting the ability of EDOs to hire employees to staff a delivery unit. It is 
quite possible that delivery units at the EDO level will have to consist of one individual driving delivery and performance. It is also possible that the deliverology approach is viable for larger urban communities, but less feasible for smaller communities in more rural settings.

A potential solution to this constraint is the possibility of creating a delivery unit for all municipal functions. This would include driving economic development delivery, but also planning, community services, by-law, etc. This solution would harmonize service delivery for all municipal services, result in cost-savings, and potentially make a delivery unit more affordable for smaller communities. The receptiveness of other municipal departments to such an arrangement is unknown and merits further research.

The findings of this study demonstrate that deliverology offers many potential advantages in improving the delivery and performance of EDOs. In light of the limitations identified in this study, further research on the applicability of deliverology in a real-world setting is necessary. A case study in a large urban municipal EDO would be the most likely methodological candidate for further study.

\section{Author biography}

Dr. Trevin S. Stratton is the Chief Economist at the Canadian Chamber of Commerce. He previously held the position of National Lead for Economic Development at BDO Canada. Trevin's research has been published in Routledge's International Studies in Business History, cited in NATO's Strategic Foresight Analysis, and taught at Harvard University's Kennedy School of Government. He has held appointments as an International Scholar at Yale University's Jackson Institute for Global Affairs, as an E.C. Harwood Fellow at the American Institute for Economic Research, and as a lecturer in politics, economics, and international studies at the American University in Dubai.

\section{References}

Ammons, D. \& Morgan, J. (2011, June). State-of-the-art measures in economic development. PM Magazine, 93(5), 6-10.

Barber, M., Rodriguez, N., \& and Artis, E. (2016). Deliverology in practice: How education leaders are improving student outcomes. Thousand Oaks: Corwin.

Barber, M., Kihn, P., \& Moffitt, A. (2011a). Deliverology: From idea to implementation. Retrieved from https://www.mckinsey.com/industries/public-sector/our-insights/deliverologyfrom-idea-to-implementation

Barber, M., Kihn, P., \& Moffitt, A. (2011b). Deliverology 101: A field guide for educational leaders. Thousand Oaks: Corwin. 
Blais, P. \& Redden, A. (2009, February). Investing in economic development: Important key indicators municipalities should assess. Municipal World, 19-21.

Blakely, E. \& Leigh, N.G. (2009). Planning local economic development: Theory and practice. Thousand Oaks: SAGE.

Bowen, W., Rubin, H. \& Hill, E. (1991). Management of economic development. Managing local government: Public administration in practice. Newbury Park: SAGE.

Cain, T., Risser, M. \& Stratton, T. (2011, March). The governance continuum: Origins and conceptual construct. Retrieved from https://iog.ca/docs/the_governance_continuum_a_pgex_working_paper_pd_18577.pdf

Donahue, R. \& McDearman, B. (2016, August 30). Performance measurement in economic development: Even the standard can't live up to the standard. Retrieved from https://www.brookings.edu/blog/the-avenue/2016/08/30/performance-measurement-ineconomic-development-even-the-standard-cant-live-up-to-the-standard/

Douglas, D.J.A. \& Chadwick, S.J. (2003). Toward more effective rural economic development in Ontario. Guelph: School of Environmental Design and Rural Development.

Economic Developers Association of Canada. (2011, September). Performance measurement in economic development: Development of performance measurements systems for local and regional economic development organizations. Retrieved from http://edac.ca/wpcontent/uploads/2014/03/Final-Report-Oct-20-Performance-Measurement-in-EconomicDevelopment-EDAC-Project-Sept-version_Addition_May7_2013.pdf

Frith, S. (1993). Analysis of organization structure of local economic development in Ontario. Waterloo: University of Waterloo.

Hatry, H.P. (2006). Performance measurement: Getting results. Washington DC: Urban Institute Press.

Ghosh, S. \& Chen, J. (2014, February 3). Making it count: Metrics for high performing EDOs. Washington DC: IEDC.

Myhal, N. (1994). Existing rationales for agencies, boards, and commissions. In D. Richmond \& D. Siegel (Eds.), Agencies, boards and commissions in Canadian local government (37-48).

Toronto: Institute of Public Administration of Canada.

Ontario Ministry of Agriculture, Food and Rural Affairs. (2015). Measuring Up! Performance Measurement for Economic Development, A Guidebook for Economic Development Practitioners. Retrieved from http://www.omafra.gov.on.ca/english/rural/edr/pmr/index.html 
Parker, P. \& Donaher, E. (2013). Comparing economic development corporation and internal models: Service delivery in Southern Ontario. Canadian Papers in Economic Development, 13, $1-34$.

Peterson, P. (1981). City limits. Chicago: University of Chicago Press.

Rubin, H.J. (1999). Shoot anything that flies; claim anything that falls: Conversations with economic development practitioners. In J.P. Blair \& L.A. Reese (Eds.), Approaches to economic development: Readings from economic development quarterly (263-278). Thousand Oaks: SAGE.

Siegel, D. (1994). The ABCs of Canadian local government: An overview. In D. Richmond \& D. Siegel (Eds.), Agencies, boards and commissions in Canadian local government (83-110). Toronto: Institute of Public Administration of Canada.

Thompson, S. (2010). Delivery models of local economic development: An analysis of internal and external models in Ontario. Canadian Papers in Economic Development, 12, 86-110.

Union of British Columbia Municipalities. (2010, April). Evaluating the economic development role of BC local governments: A snapshot of community effort and opportunity. Retrieved from https://www.ubcm.ca/assets/Resolutions and Policy/Policy/Community Economic Developme nt/UBCM\%20ED\%20REPORT\%204-14.pdf 